\title{
Spatial memory deficit across aging: current insights of the role of $5-\mathrm{HT}_{7}$ receptors
}

\section{Gregory Beaudet, Valentine Bouet, Christelle Jozet-Alves, Pascale Schumann-Bard, François Dauphin, Eleni Paizanis, Michel Boulouard and Thomas Freret*}

Université de Caen Basse-Normandie, Groupe Mémoire et Plasticité Comportementale (GMPC), EA 4259, Caen, France

\section{Edited by:}

Walter Adriani, Istituto Superiore di

Sanità, Italy

Reviewed by:

Alfredo Meneses, Center for

Research and Advanced Studies,

Mexico

Francesca Zoratto, Istituto

Superiore di Sanità, Italy

${ }^{*}$ Correspondence:

Thomas Freret, Université de Caen Basse-Normandie, Groupe Mémoire et Plasticité Comportementale (GMPC), EA 4259, Boulevard Henri Becquerel, F-14032 Caen, France e-mail: thomas.freret@unicaen.fr

\begin{abstract}
Elderly persons often face biological, psychological or social changes over time that may cause discomfort or morbidity. While some cognitive domains remain stable over time, others undergo a decline. Spatial navigation is a complex cognitive function essential for independence, safety and quality of life. While egocentric (body-centered) navigation is quite preserved during aging, allocentric (externally-centered) navigation-based on a cognitive map using distant landmarks-declines with age. Recent preclinical studies showed that serotonergic $5-\mathrm{HT}_{7}$ receptors are localized in brain regions associated with allocentric spatial navigation processing. Behavioral assessments with pharmacological or genetic tools have confirmed the role of $5-\mathrm{HT}_{7}$ receptors in allocentric navigation. Moreover, few data suggested a selective age-related decrease in the expression of $5-\mathrm{HT}_{7}$ receptors in pivotal brain structures implicated in allocentric navigation such as the hippocampal CA3 region. We aim to provide a short overview of the potential role of $5-\mathrm{HT}_{7}$ receptors in spatial navigation, and to argue for their interests as therapeutic targets against age-related cognitive decline.
\end{abstract}

Keywords: spatial cognition, Alzheimer's disease, serotonin, aging, $5-\mathrm{HT}_{7} \mathrm{R}$
The world's population is aging at an unprecedented rate and constitutes a significant public health issue. Aging is associated with the decline in selective aspects of cognitive performance, together with brain functional and anatomical changes. Among cognitive functions that decline with age, spatial navigation is impaired after the age of 60 , with an acceleration in decline after 70 (Barrash, 1994). Spatial navigation is a complex cognitive ability that is essential for independence, safety and quality of life. Spatial navigation capacities have also recently attracted attention in the field of neurodegenerative disorders, especially Alzheimer's disease (AD; Lithfous et al., 2013). Indeed, from a clinical point of view, diagnosis of $\mathrm{AD}$ in very early stages appears to be a crucial challenge to optimize therapeutic management. The modulation of the last discovered serotonin receptors, 5-hydroxytryptamine receptors type 7 or $5-\mathrm{HT}_{7} \mathrm{R}$, might be a promising therapeutic approach.

\section{EGOCENTRIC VS. ALLOCENTRIC SPATIAL STRATEGY SHIFT ACROSS AGING}

Spatial navigation refers to the process of determining and maintaining a course or trajectory to a goal location (Franz and Mallot, 2000). Two main kinds of strategies are commonly distinguished, depending on the frame of reference used to encode location: egocentric vs. allocentric (Zaehle et al., 2007). When using an egocentric frame of reference, spatial information is encoded from the viewpoint of the individual: it corresponds to self-centered navigation. For example, an egocentric strategy can refer to the association between a particular landmark and left or right body turn in response to this landmark (e.g., turn right at the bookshop, then turn left at the museum). Allocentric navigation is based on non-self-centered maps, i.e., independent of the individual position (O'Keefe and Nadel, 1978). The individual memorizes spatial relationships between landmarks, such as relative direction, angle and distances (Dolins and Mitchell, 2010). Unlike egocentric strategies, allocentric strategies enable an individual to plan novel routes during navigation.

Among the numerous experimental procedures designed to assess spatial learning abilities, most of them allow only one kind of strategy to be used. However, some paradigms offer the opportunity to use either an egocentric or an allocentric strategy (Paul et al., 2009). Several studies have shown that even though individuals spontaneously select one strategy, they are still able to switch when necessary (humans: Iaria et al., 2003; Etchamendy and Bohbot, 2007; Iglói et al., 2009; rodents: Gibson and Shettleworth, 2005). Thus, this coexistence of strategies allows individuals to adapt themselves to environmental constraints, by shifting for instance from one strategy to another when some spatial information becomes unreliable (Healy, 1998; Shettleworth, 2009).

Functional neuroimaging and neuropsychological studies have provided evidence that the hippocampus and para-hippocampal areas are critically involved when using an allocentric frame of reference (Bohbot et al., 1998; Maguire et al., 1998; Moffat et al., 2006). Conversely, right-sided parietal association cortices and subcortical regions, especially the striatum (i.e., caudate 
nucleus and putamen), are commonly associated with egocentric strategies (Maguire et al., 1998; Hartley et al., 2003; Iaria et al., 2003; Galati et al., 2010). Indeed, while performing a spatial task that offers the choice between the two strategies, the subjects who preferentially use an allocentric strategy display a high activity in the right hippocampus; whereas higher brain activity is observed in the caudate nucleus when the egocentric strategy was preferentially adopted (Iaria et al., 2003). Similar results have been observed in preclinical studies. Through the use of different experimental approaches (lesional, transient inactivation or pharmacological experiments), animal data suggested that egocentric and allocentric strategies rely on different neural networks in rodents: the dorso-striatal and the hippocampal mnesic systems, respectively (Packard and McGaugh, 1992; Packard, 1999; DeCoteau and Kesner, 2000; Miranda et al., 2006; Burgess, 2008). When performing a behavioral task in which both strategies are efficient, a higher neuronal activity (assessed through phospho-CREB immunoreactivity) is observed in the dentate gyrus, hippocampal CA1 and CA3 of rats preferentially using an allocentric strategy. Conversely, dorso-lateral and dorso-medial striatum are more activated in rats preferentially using an egocentric strategy. This parallel functioning is however not always straightforward, since both strategies rely on, at least, some shared brain structures. In humans, the posterior parietal and the frontal cortex appear to be activated both in individuals preferring an egocentric or an allocentric strategy (Iaria et al., 2003). In rodents, although the CA3 is activated when using an allocentric strategy, and conversely the striatum when using an egocentric strategy, the dentate gyrus and mammillary bodies are activated in both cases (Rubio et al., 2012; see Table 1).

Advanced age is known to alter spatial cognitive abilities (Moffat, 2009; Klencklen et al., 2012). Thus, healthy elders have poorer performances than their younger counterparts when learning a route (i.e., egocentric strategy) (Moffat et al., 2001; Wiener et al., 2013). Depending on the procedure used, this impairment is not always observed (Etchamendy et al., 2012; Gazova et al., 2013), or sometimes remains quite moderate (Pouliot and Gagnon, 2005). However, when addressing allocentric navigation (using either real or virtual environments), agerelated impairments are more systematically observed (Moffat and Resnick, 2002, 2007; Driscoll et al., 2003, 2005; Iaria et al., 2009; Gazova et al., 2013). In addition, compared to children, the proportion of subjects preferentially choosing an allocentric strategy in a spatial task is decreased in elders (Bohbot et al., 2012; Rodgers et al., 2012). Aging seems to specifically impair the ability of switching to an allocentric strategy, when an egocentric strategy becomes unreliable (Harris et al., 2012). All results above are consistent with animal studies, showing age-related impairments when using an allocentric strategy (Gallagher and Pelleymounter, 1988; Begega et al., 2001). Additionally, even if aged mice are still able to use an allocentric strategy, they preferentially use an egocentric strategy when they have the opportunity to choose (Nicolle et al., 2003). According to Klencklen et al., impairments observed in egocentric tasks may be due to deficits in the planning of the pathway, while deficits observed in allocentric tasks may be due to the lower likelihood of elderly people to learn configurational information about the environment (Klencklen et al., 2012).

Several studies have been performed to better understand the neural mechanisms underlying age-related alteration in spatial abilities. From a neuroanatomical point-of-view regarding ageinduced changes, a shrinkage of the caudate nucleus as well as a greatest deterioration of the frontal cortex are among the two modifications the most frequently documented and welladmitted (Raz et al., 1997, 2003; Greenberg et al., 2008; Kalpouzos et al., 2009; Walhovd et al., 2011). In regards to the hippocampus, while most studies found a shrinkage with aging (Du et al., 2006), some did not found any (Good et al., 2001). This discrepancy may be due to the sampling method used: e.g., studies undertaken across a wide spread of ages (e.g., from 18 to 79 in Good et al., 2001) vs. key periods of age-related impairments (e.g., from 58 to 87 years old in Du et al., 2006; Kalpouzos et al., 2009). Beyond these differences, it seems that shrinkage is usually observed across aging only when considering the posterior part of the hippocampus. Hippocampal neuronal integrity has also been shown to be altered in elderly subjects (Driscoll et al., 2003), and a reduced resting-state metabolism has been observed (Small et al., 2002). Moreover, a reduced activation of the neural network underlying allocentric strategy was observed in older adults (Moffat et al., 2006). Konishi and Bohbot showed that the volume of gray matter in the hippocampus positively correlates with spontaneous allocentric strategies in the healthy elderly (Konishi and Bohbot, 2013). Structural, neurochemical and functional agerelated changes in hippocampus and associated structures may explain why impairments are observed in allocentric strategies in the elderly.

\section{5-HT 7 RECEPTORS AND SPATIAL NAVIGATION}

The $5-\mathrm{HT}_{7} \mathrm{R}$ belong to the superfamily of G-protein-coupled receptors. Since their discovery, almost 20 years ago, $5-\mathrm{HT}_{7} \mathrm{R}$ distribution has been accurately investigated both in humans and in non-human species (human: Varnäs et al., 2004; non-human: To et al., 1995; Waeber and Moskowitz, 1995; Gustafson et al., 1996; Neumaier et al., 2001; Bonaventure et al., 2004). Even though slight differences can emerge according to the protocols or the techniques used-immunohistochemistry, radiolabelling, qPCR, etc. ., the central distribution of $5-\mathrm{HT}_{7} \mathrm{R}$ is generally in accordance within the three mainly studied species (human, rat and guinea pig) (Leopoldo et al., 2011). In the central nervous system, a higher density of $5-\mathrm{HT}_{7} \mathrm{R}$ was found in the hippocampus (particularly in the CA3 and the dentate gyrus, and to a lesser extent in the CA1), in the hypothalamus and in the thalamus (particularly within the anterior part). Additionally, $5-\mathrm{HT}_{7} \mathrm{R}$ are also broadly-but less densely-distributed in the cortex, especially in the frontal, piriform and cingulate cortices, as well as in the amygdala and the dorsal raphe nucleus. As regards to its expression in basal ganglia nuclei, results show discrepancies across species. In humans, a high concentration is observed in caudate and putamen nuclei, whereas the striatum appears to be a structure with low $5-\mathrm{HT}_{7} \mathrm{R}$ expression in rats (Martín-Cora and Pazos, 2004). 
Table 1 | Relative abundance of $5-\mathrm{HT}_{7} \mathrm{R}$ within brain structures involved in egocentric and/or allocentric spatial strategies, and evolution of $5-\mathrm{HT}_{7} \mathrm{R}$ mRNA expression across aging.

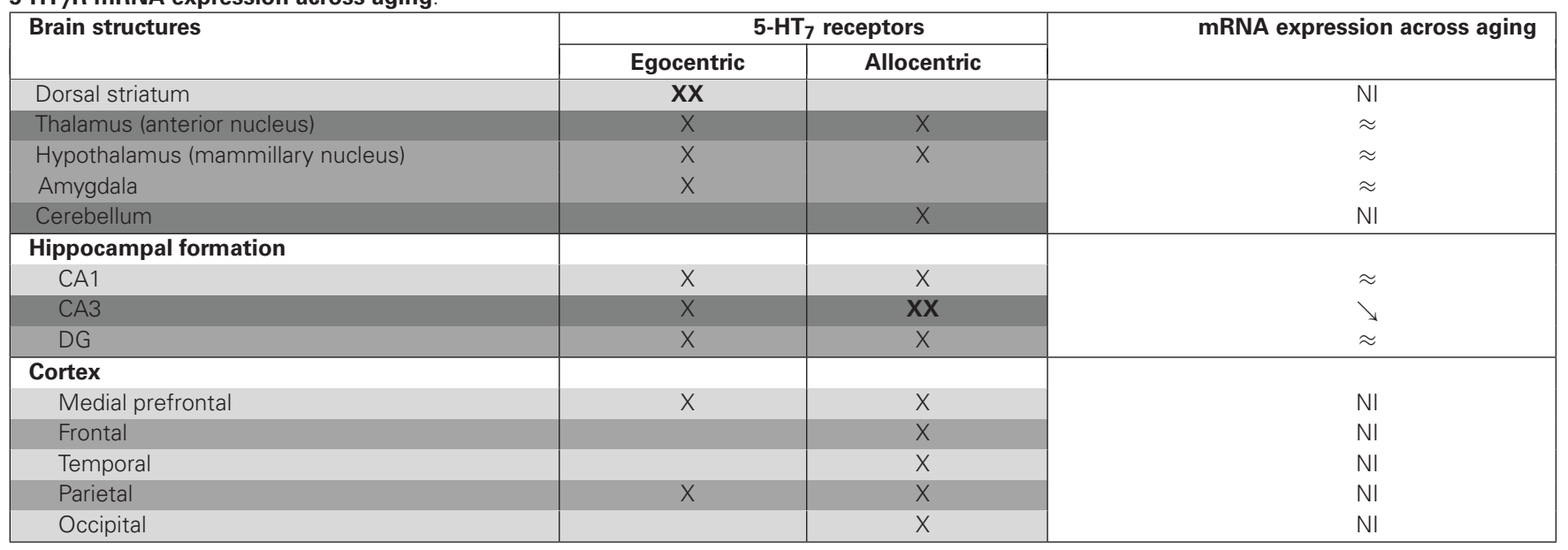

Relative density of $\mathbf{5 - H T _ { 7 }} \mathbf{R}$ :

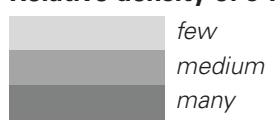

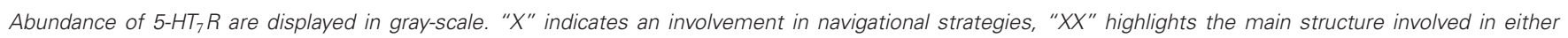

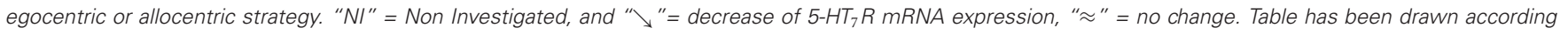
to the following publications in animals: (To et al., 1995; Gustafson et al., 1996; Duncan et al., 1999; Yau et al., 1999; Kohen et al., 2000; Begega et al., 2001, 2012; Neumaier et al., 2001; Moffat and Resnick, 2002; Colombo et al., 2003; Bonaventure et al., 2004; Varnäs et al., 2004; Moffat et al., 2006; Duncan and Franklin, 2007; Rubio et al., 2012).

Given their distribution within the central nervous system, several recent experiments support a role for $5-\mathrm{HT}_{7} \mathrm{R}$ in learning and memory processes (for review see Meneses, 2013). Most interestingly, it seems that $5-\mathrm{HT}_{7} \mathrm{R}$ plays a major role in hippocampusdependent memory processing (Roberts et al., 2004; Gasbarri et al., 2008; Sarkisyan and Hedlund, 2009), particularly when learning a location is required to solve the task This has notably been observed while using two different paradigms of the object recognition test. Typically, the test consisted in two consecutive sessions separated by an intersession interval, and is carried out in an open-field. During the first session, animal can freely explore two similar objects. During the second session, according to the paradigm used, one of the two objects is either replaced by a new one (this paradigm is called novel object recognition test), or only displaced (this paradigm is called object-place recognition test (Oliveira et al., 2010)). The difference between those two paradigms of recognition task relies on the more pronounced involvement of the hippocampus in the object-place recognition test (Barker and Warburton, 2011). In the "novel" object recognition test, transgenic $5-\mathrm{HT}_{7} \mathrm{R}$ knock-out (KO) mice performed similarly to their wild-type siblings (Sarkisyan and Hedlund, 2009). As a contrary, in the object-place recognition test, while the spatial component of the test is more challenging, $\mathrm{KO}$ mice displayed a marked impairment of memory performances. Of note, the same hold true if wild mice are administered before the first session, with SB-269970, a selective 5- $\mathrm{HT}_{7} \mathrm{R}$ antagonist. Indeed, whereas no differences are noticed for the non-spatial paradigm of the test (novel object recognition) when the antagonist is administrated, impairments are observed in the spatial version of the recognition task (Sarkisyan and Hedlund, 2009).
Thus, those two results obtained with either $\mathrm{KO}$ mice or after administration of $5-\mathrm{HT}_{7} \mathrm{R}$ antagonist both argue for a predominant role of $5-\mathrm{HT}_{7} \mathrm{R}$ in behavioral tasks requiring animals to learn location of objects in an allocentric frame of reference. Still in the context of pharmacological modulation of $5-\mathrm{HT}_{7} \mathrm{R}$, a sub-chronic treatment during adolescence withLP-211 (a selective $5-\mathrm{HT}_{7} \mathrm{R}$ agonist) did not lead to major modifications of performances in the novel object recognition paradigm at adulthood (Canese et al., 2014). Unfortunately, the effect of an acute tonic pharmacological modulation of $5-\mathrm{HT}_{7} \mathrm{R}$ has yet not been investigated in the two paradigms of the recognition test. Again, such a result is in favor of an involvement of $5-\mathrm{HT}_{7} \mathrm{R}$ in memory processes when spatial learning is required.

Beyond the importance of the spatial component in the behavioral task, the involvement of $5-\mathrm{HT}_{7} \mathrm{R}$ could also vary according to the strategy used to perform the test. In fact, $\mathrm{KO}$ mice have been tested in the Barnes maze test (Roberts et al., 2004; Sarkisyan and Hedlund, 2009). This dry-land maze consists of a brightly illuminated elevated circular platform (aversive stimulation), with several holes around its perimeter (Barnes, 1979). Each session of the test starts by placing the animal in the middle of the maze. Animals will then try to escape the aversive bright light maze by searching and entering into the box placed underneath one of the holes. Even though egocentric and allocentric strategies are both efficient in this test (Harrison et al., 2006), a recent study has demonstrated that all of the 13 inbred strains of mice tested preferentially used an egocentric strategy to find the platform (O'Leary et al., 2011). In this task, KO mice did no display any spatial memory impairment (Roberts et al., 2004; Sarkisyan and Hedlund, 2009). Thus, this lack of deficit might be explained by 
the use of a striatum-dependent egocentric strategy, spared in these KO mice (Sarkisyan and Hedlund, 2009). Besides, it has been elegantly demonstrated that KO mice displayed a clear deficit in allocentric strategy. Indeed, Sarkisyan and Hedlund performed a reversal test a month later during which the location of the escape box was moved $180^{\circ}$ away from its original location. As expected, all mice started looking for the escape box at its original quadrant. But, after having explored the now empty hole, the two populations of mice ( $\mathrm{KO}$ and wild-type) started to explore the maze in a quite different manner. Indeed, while $\mathrm{KO}$ mice found themselves close to the starting position, they continued to use the initial pathway to come back to the empty escape box. Such observation led the authors to hypothesize that $\mathrm{KO}$ mice may not be able to switch to an allocentric strategy, so keep using an egocentric one, even though it is no longer reliable. Such behavioral impairments observed in $\mathrm{KO}$ mice might be related to the absence of expression of $5-\mathrm{HT}_{7} \mathrm{R}$ in the CA3 region of the hippocampus and dentate gyrus. Indeed, those two regions are mainly involved in the integration of environmental changes. Besides, in wild type mice, a high density of $5-\mathrm{HT}_{7} \mathrm{R}$ is observed in the CA3 region of the hippocampus and dentate gyrus, relative to other brain regions. Thus, the lack of expression of $5-\mathrm{HT}_{7} \mathrm{R}$ within those two brain regions in $\mathrm{KO}$ mice would have led to an impairment of allocentric strategy. Unfortunately, the authors did not test this hypothesis with another group of wild-type mice within the same experimental paradigm, but with the presence of a wall around the edge of the maze. Such a group is considered as a "negative control". Indeed, in such condition, since no external visual cue is available, animals are forced to use an egocentric strategy at every step of the test.

Finally, the group of Meneses also investigated the involvement of $5-\mathrm{HT}_{7} \mathrm{R}$ in another spatial task, namely the radial arm maze (Gasbarri et al., 2008). In this work, authors observed conflicting results to what we previously described. Indeed, they showed that the pharmacological blockade of $5-\mathrm{HT}_{7} \mathrm{R}$ (SB269970) improved spatial learning performances. Thus, the same pharmacological agent (namely SB-269970) has been demonstrated both to improve (Gasbarri et al., 2008) (see above) or to impair spatial memory performances (Sarkisyan and Hedlund, 2009). Roberts and Hedlund have suggested an explanation that allows for overcoming discrepancies (Roberts and Hedlund, 2012). In fact, in the radial arm maze experiment, the animal is always placed at the center of the maze at the beginning of each session. Thus, they suggested that learning the location of the baited-arm through an egocentric strategy (a direct route from the starting position) could be more efficient than the allocentric one. If this is true, then the better performances observed in treated rats may be explained by the fact that SB269970 would have favored a more rigid strategy (independent of $\left.5-\mathrm{HT}_{7} \mathrm{R}\right)$.

\section{5-HT 7 R ACROSS AGING: INSIGHT TO A POTENTIAL THERAPEUTIC TARGET?}

Surprisingly, only a few studies have examined changes in brain $5-\mathrm{HT}_{7} \mathrm{R}$ density during aging, with only five publications from three different research groups available so far. Unfortunately, the results are not straightforward. The first publication comes from the Seckl lab which used a pharmacological model of adrenalectomy in order to mimic accelerated aging in rats (Yau et al., 1997). In this work, the authors observed, through in situ hybridization, an increased expression of $5-\mathrm{HT}_{7} \mathrm{R}$ mRNA expression in the hippocampal CA3 regions $24 \mathrm{~h}$ after the induction of the experimental model (Yau et al., 1997). However, when 2 years later the same group performed the same experiments but in aged rats (22-24 months), no modification was observed in any of the hippocampal sub-regions (Yau et al., 1999). This apparent discrepancy seems thus more related on the relevance, in the context of $5-\mathrm{HT}_{7} \mathrm{R}$, of the pharmacological model used in the first study in order to mimic aging processes. Kohen et al. have also explored changes in $5-\mathrm{HT}_{7} \mathrm{R}$ density across aging in three groups of rats, aged either 3, 12 or 24 months, modeling different stages of aging; adult, middle-aged and old, respectively (Kohen et al., 2000). In this work, the authors have studied the subfields of the hippocampus by separating the ventral and dorsal part. In accordance to the work of Yau et al. in aged rats (Yau et al., 1999), the authors did not observe any change in the dorsal CA3 of the hippocampus. However, they noticed an age-related decline in the ventral CA3 part of the hippocampus. This decrease, already marked in the middle-aged group of rats, remained the same in old rats (24 months). Finally, using another animal model (hamsters), Duncan and Franklin also investigated the effect of aging on mRNA expression of $5-\mathrm{HT}_{7} \mathrm{R}$ in discrete forebrain and midbrain regions (Duncan and Franklin, 2007). Three age groups of hamsters $(3-5,12-14$ and 17-19 months of age) were also studied. Contrary to what was previously observed, this work has not highlighted alteration of mRNA expression across aging in any of the investigated brain regions-including the hippocampus, with the exception of the decrease measured in the cingulate cortex and the paraventricular thalamic nucleus. In a previous study which focused in four brain structures that regulate circadian cycle (namely the suprachiamastic nuclei, the lateral geniculated nuclei, the median raphe nucleus and dorsal raphe nucleus), the same group of researchers also observed a marked decrease in $5-\mathrm{HT}_{7} \mathrm{R}$ in the dorsal raphe nucleus (Duncan et al., 1999). As regards to expression of $5-\mathrm{HT}_{7} \mathrm{R}$ mRNA in the hippocampus, several explanations can be proposed to explain discrepancies observed in the effects of aging. Indeed, the different animal models used (rats, mice, hamsters) may account for such divergent results, as well as, for instance, the location of the brain slice performed in the different works (highlighting or masking discrete regions of interest), etc... Besides, one may note that when comparing the works of the group of Yau and Kohen, if the whole structure is taken into account, no age-induced modification is observed, whereas a marked decreased of approximately $30 \%$ is well observed when focusing in the ventral part of the hippocampus. Considering the role of the CA3 region of the hippocampus in spatial strategy highlighted above, a decreased expression of $5-\mathrm{HT}_{7} \mathrm{R}$ in this brain structure could account for impairments of the shift between spatial strategies across aging.

\section{CONCLUSION AND FUTURE DIRECTIONS}

Regarding the question of aging-induced deficit in the shift between egocentric and allocentric strategies and the role of 
$5-\mathrm{HT}_{7} \mathrm{R}$ in these impairments, a crucial lack of data makes it difficult to draw conclusions presently. Indeed, all the previously cited studies exploring the changes of $5-\mathrm{HT}_{7} \mathrm{R}$ across aging have occurred at the messenger RNA level; but not at the level of the final product, i.e., the protein. Indeed, changes in posttranscriptional and/or translational regulation mechanisms may lead to divergent observations between those two levels. In fact, this has already been observed in the context of $5-\mathrm{HT}_{7} \mathrm{R}$. Thus, in 2007, Duncan and Franklin have not shown any age-induced modification of $5-\mathrm{HT}_{7} \mathrm{R}$ mRNA expression in the dorsal raphe nuclei (Duncan and Franklin, 2007). However, the same group of researchers observed a marked decrease of $50 \%$ at the protein level of $5-\mathrm{HT}_{7} \mathrm{R}$ in dorsal raphe nuclei in a prior study (Duncan et al., 1999). Thus, changes in the level of transcription of the $5-\mathrm{HT}_{7} \mathrm{R}$ mRNA did not account for the age-related difference observed at the protein level, at least in this brain structure. Besides, $5-\mathrm{HT}_{7} \mathrm{R}$ might also be putatively subjected, across aging, to modifications in their affinity or to changes in their coupling to G-proteins or other signaling pathways. In fact, such an effect has already been suggested by Duncan et al. (2004). Thus, even though a lack of data prevents us from drawing strong conclusions about the role of $5-\mathrm{HT}_{7} \mathrm{R}$ in the shift from spatial strategies across aging, those receptors appear to be promising target given their known locations in cerebral structures affected by aging processes, and their demonstrated role in spatial paradigms requiring the use of an allocentric strategy.

\section{ACKNOWLEDGMENTS}

The authors wish to thank Caitlin O’Brien for her English-editing advice.

\section{REFERENCES}

Barker, G. R. I., and Warburton, E. C. (2011). When is the hippocampus involved in recognition memory? J. Neurosci. 31, 10721-10731. doi: 10.1523/JNEUROSCI. 6413-10.2011

Barnes, C. A. (1979). Memory deficits associated with senescence: a neurophysiological and behavioral study in the rat. J. Comp. Physiol. Psychol. 93, 74-104. doi: $10.1037 / \mathrm{h} 0077579$

Barrash, J. (1994). Age-related decline in route learning ability. Dev. Neuropscyhol. 10, 189-201. doi: 10.1080/87565649409540578

Begega, A., Cienfuegos, S., Rubio, S., SantíN, J. L., Miranda, R., and Arias, J. L. (2001). Effects of ageing on allocentric and egocentric spatial strategies in the Wistar rat. Behav. Processes 53, 75-85. doi: 10.1016/s0376-6357(00)00150-9

Begega, A., Cuesta, M., Rubio, S., Méndez, M., Santín, L. J., and Arias, J. L. (2012). Functional networks involved in spatial learning strategies in middle-aged rats. Neurobiol. Learn. Mem. 97, 346-353. doi: 10.1016/j.nlm.2012.02.007

Bohbot, V. D., Kalina, M., Stepankova, K., Spackova, N., Petrides, M., and Nadel, L. (1998). Spatial memory deficits in patients with lesions to the right hippocampus and to the right parahippocampal cortex. Neuropsychologia 36, 1217-1238. doi: 10.1016/s0028-3932(97)00161-9

Bohbot, V. D., Mckenzie, S., Konishi, K., Fouquet, C., Kurdi, V., Schachar, R., et al. (2012). Virtual navigation strategies from childhood to senescence: evidence for changes across the life span. Front. Aging Neurosci. 4:28. doi: 10.3389/fnagi.2012. 00028

Bonaventure, P., Nepomuceno, D., Hein, L., Sutcliffe, J. G., Lovenberg, T., and Hedlund, P. B. (2004). Radioligand binding analysis of knockout mice reveals 5-hydroxytryptamine(7) receptor distribution and uncovers 8-hydroxy-2-(din-propylamino)tetralin interaction with alpha(2) adrenergic receptors. Neuroscience 124, 901-911. doi: 10.1016/j.neuroscience.2004.01.014

Burgess, N. (2008). Spatial cognition and the brain. Ann. N Y Acad. Sci. 1124, 7797. doi: 10.1196/annals. 1440.002

Canese, R., Zoratto, F., Altabella, L., Porcari, P., Mercurio, L., De Pasquale, F., et al. (2014). Persistent modification of forebrain networks and metabolism in rats following adolescent exposure to a 5-HT7 receptor agonist. Psychopharmacology (Berl) doi: 10.1007/s00213-014-3639-6. [Epub ahead of print].

Colombo, P. J., Brightwell, J. J., and Countryman, R. A. (2003). Cognitive strategy-specific increases in phosphorylated cAMP response element-binding protein and c-Fos in the hippocampus and dorsal striatum. J. Neurosci. 23, 3547-3554.

DeCoteau, W. E., and Kesner, R. P. (2000). A double dissociation between the rat hippocampus and medial caudoputamen in processing two forms of knowledge. Behav. Neurosci. 114, 1096-1108. doi: 10.1037//0735-7044.114. 6.1096

Dolins, F. L., and Mitchell, R. W. (2010). Spatial Cognition, Spatial Perception: Mapping the Self and Space. Cambridge: Cambridge University Press.

Driscoll, I., Hamilton, D. A., Petropoulos, H., Yeo, R. A., Brooks, W. M., Baumgartner, R. N., et al. (2003). The aging hippocampus: cognitive, biochemical and structural findings. Cereb. Cortex 13, 1344-1351. doi: 10.1093/cercor/ bhg081

Driscoll, I., Hamilton, D. A., Yeo, R. A., Brooks, W. M., and Sutherland, R. J. (2005). Virtual navigation in humans: the impact of age, sex and hormones on place learning. Horm. Behav. 47, 326-335. doi: 10.1016/j.yhbeh.2004.11.013

Du, A.-T., Schuff, N., Chao, L. L., Kornak, J., Jagust, W. J., Kramer, J. H., et al. (2006). Age effects on atrophy rates of entorhinal cortex and hippocampus. Neurobiol. Aging 27, 733-740. doi: 10.1016/j.neurobiolaging.2005. 03.021

Duncan, M. J., and Franklin, K. M. (2007). Expression of 5-HT7 receptor mRNA in the hamster brain: effect of aging and association with calbindinD28K expression. Brain Res. 1143, 70-77. doi: 10.1016/j.brainres.2007. 01.044

Duncan, M. J., Grear, K. E., and Hoskins, M. A. (2004). Aging and SB-269970-A, a selective 5-HT7 receptor antagonist, attenuate circadian phase advances induced by microinjections of serotonergic drugs in the hamster dorsal raphe nucleus. Brain Res. 1008, 40-48. doi: 10.1016/j.brainres.2004.02.025

Duncan, M. J., Short, J., and Wheeler, D. L. (1999). Comparison of the effects of aging on 5-HT7 and 5-HT1A receptors in discrete regions of the circadian timing system in hamsters. Brain Res. 829, 39-45. doi: 10.1016/s00068993(99)01311-6

Etchamendy, N., and Bohbot, V. D. (2007). Spontaneous navigational strategies and performance in the virtual town. Hippocampus 17, 595-599. doi: 10.1002/hipo. 20303

Etchamendy, N., Konishi, K., Pike, G. B., Marighetto, A., and Bohbot, V. D. (2012). Evidence for a virtual human analog of a rodent relational memory task: a study of aging and fMRI in young adults. Hippocampus 22, 869-880. doi: 10. 1002/hipo.20948

Franz, M. O., and Mallot, H. A. (2000). Biomimetic robot navigation. Rob. Auton. Syst. 30, 133-153. doi: 10.1016/s0921-8890(99)00069-x

Galati, G., Pelle, G., Berthoz, A., and Committeri, G. (2010). Multiple reference frames used by the human brain for spatial perception and memory. Exp. Brain Res. 206, 109-120. doi: 10.1007/s00221-010-2168-8

Gallagher, M., and Pelleymounter, M. A. (1988). Spatial learning deficits in old rats: a model for memory decline in the aged. Neurobiol. Aging 9, 549-556. doi: 10. 1016/s0197-4580(88)80112-x

Gasbarri, A., Cifariello, A., Pompili, A., and Meneses, A. (2008). Effect of 5-HT7 antagonist SB-269970 in the modulation of working and reference memory in the rat. Behav. Brain Res. 195, 164-170. doi: 10.1016/j.bbr.2007.12.020

Gazova, I., Laczó, J., Rubinova, E., Mokrisova, I., Hyncicova, E., Andel, R., et al. (2013). Spatial navigation in young versus older adults. Front. Aging Neurosci. 5:94. doi: 10.3389/fnagi.2013.00094

Gibson, B. M., and Shettleworth, S. J. (2005). Place versus response learning revisited: tests of blocking on the radial maze. Behav. Neurosci. 119, 567-586. doi: 10.1037/0735-7044.119.2.567

Good, C. D., Johnsrude, I. S., Ashburner, J., Henson, R. N., Friston, K. J., and Frackowiak, R. S. (2001). A voxel-based morphometric study of ageing in 465 normal adult human brains. Neuroimage 14, 21-36. doi: 10.1006/nimg.2001. 0786

Greenberg, D. L., Messer, D. F., Payne, M. E., Macfall, J. R., Provenzale, J. M., Steffens, D. C., et al. (2008). Aging, gender and the elderly adult brain: an examination of analytical strategies. Neurobiol. Aging 29, 290-302. doi: 10. 1016/j.neurobiolaging.2006.09.016

Gustafson, E. L., Durkin, M. M., Bard, J. A., Zgombick, J., and Branchek, T. A. (1996). A receptor autoradiographic and in situ hybridization analysis of the 
distribution of the 5-ht7 receptor in rat brain. Br. J. Pharmacol. 117, 657-666. doi: 10.1111/j.1476-5381.1996.tb15241.x

Harris, M. A., Wiener, J. M., and Wolbers, T. (2012). Aging specifically impairs switching to an allocentric navigational strategy. Front. Aging Neurosci. 4:29. doi: 10.3389/fnagi.2012.00029

Harrison, F. E., Reiserer, R. S., Tomarken, A. J., and McDonald, M. P. (2006). Spatial and nonspatial escape strategies in the Barnes maze. Learn. Mem. 13, 809-819. doi: 10.1101/lm.334306

Hartley, T., Maguire, E. A., Spiers, H. J., and Burgess, N. (2003). The wellworn route and the path less traveled: distinct neural bases of route following and wayfinding in humans. Neuron 37, 877-888. doi: 10.1016/s08966273(03)00095-3

Healy, S. (1998). Spatial Representation in Animals. New York, NY: Oxford University Press, 188.

Iaria, G., Palermo, L., Committeri, G., and Barton, J. J. S. (2009). Age differences in the formation and use of cognitive maps. Behav. Brain Res. 196, 187-191. doi: 10. 1016/j.bbr.2008.08.040

Iaria, G., Petrides, M., Dagher, A., Pike, B., and Bohbot, V. D. (2003). Cognitive strategies dependent on the hippocampus and caudate nucleus in human navigation: variability and change with practice. J. Neurosci. 23 , 5945-5952.

Iglói, K., Zaoui, M., Berthoz, A., and Rondi-Reig, L. (2009). Sequential egocentric strategy is acquired as early as allocentric strategy: parallel acquisition of these two navigation strategies. Hippocampus 19, 1199-1211. doi: 10.1002/hipo. 20595

Kalpouzos, G., Chételat, G., Baron, J.-C., Landeau, B., Mevel, K., Godeau, C., et al. (2009). Voxel-based mapping of brain gray matter volume and glucose metabolism profiles in normal aging. Neurobiol. Aging 30, 112-124. doi: 10. 1016/j.neurobiolaging.2007.05.019

Klencklen, G., Després, O., and Dufour, A. (2012). What do we know about aging and spatial cognition? Reviews and perspectives. Ageing Res. Rev. 11, 123-135. doi: 10.1016/j.arr.2011.10.001

Kohen, R., Heidmann, D. E., Anthony, J., White, S. S., Hamblin, M. W., and Szot, P. (2000). Changes in 5-HT(7) serotonin receptor mRNA expression with aging in rat brain. Brain Res. Mol. Brain Res. 79, 163-168. doi: 10.1016/s0169328x(00)00103-0

Konishi, K., and Bohbot, V. D. (2013). Spatial navigational strategies correlate with gray matter in the hippocampus of healthy older adults tested in a virtual maze. Front. Aging Neurosci. 5:1. doi: 10.3389/fnagi.2013.00001

Leopoldo, M., Lacivita, E., Berardi, F., Perrone, R., and Hedlund, P. B. (2011). Serotonin 5-HT7 receptor agents: structure-activity relationships and potential therapeutic applications in central nervous system disorders. Pharmacol. Ther. 129, 120-148. doi: 10.1016/j.pharmthera.2010.08.013

Lithfous, S., Dufour, A., and Després, O. (2013). Spatial navigation in normal aging and the prodromal stage of Alzheimer's disease: insights from imaging and behavioral studies. Ageing Res. Rev. 12, 201-213. doi: 10.1016/j.arr.2012. 04.007

Maguire, E. A., Burgess, N., Donnett, J. G., Frackowiak, R. S., Frith, C. D., and O'Keefe, J. (1998). Knowing where and getting there: a human navigation network. Science 280, 921-924. doi: 10.1126/science.280.5365.921

Martín-Cora, F. J., and Pazos, A. (2004). Autoradiographic distribution of 5HT7 receptors in the human brain using $[3 \mathrm{H}]$ mesulergine: comparison to other mammalian species. Br. J. Pharmacol. 141, 92-104. doi: 10.1038/sj.bjp. 0705576

Meneses, A. (2013). 5-HT systems: emergent targets for memory formation and memory alterations. Rev. Neurosci. 24, 629-664. doi: 10.1515/revneuro-20130026

Miranda, R., Blanco, E., Begega, A., Rubio, S., and Arias, J. L. (2006). Hippocampal and caudate metabolic activity associated with different navigational strategies. Behav. Neurosci. 120, 641-650. doi: 10.1037/0735-7044.120.3.641

Moffat, S. D. (2009). Aging and spatial navigation: what do we know and where do we go? Neuropsychol. Rev. 19, 478-489. doi: 10.1007/s11065-0099120-3

Moffat, S. D., Elkins, W., and Resnick, S. M. (2006). Age differences in the neural systems supporting human allocentric spatial navigation. Neurobiol. Aging 27, 965-972. doi: 10.1016/j.neurobiolaging.2005.05.011

Moffat, S. D., and Resnick, S. M. (2002). Effects of age on virtual environment place navigation and allocentric cognitive mapping. Behav. Neurosci. 116, 851-859. doi: 10.1037//0735-7044.116.5.851
Moffat, S. D., and Resnick, S. M. (2007). Long-term measures of free testosterone predict regional cerebral blood flow patterns in elderly men. Neurobiol. Aging 28, 914-920. doi: 10.1016/j.neurobiolaging.2006. 04.001

Moffat, S. D., Zonderman, A. B., and Resnick, S. M. (2001). Age differences in spatial memory in a virtual environment navigation task. Neurobiol. Aging 22, 787-796. doi: 10.1016/s0197-4580(01)00251-2

Neumaier, J. F., Sexton, T. J., Yracheta, J., Diaz, A. M., and Brownfield, M. (2001). Localization of 5-HT(7) receptors in rat brain by immunocytochemistry, in situ hybridization and agonist stimulated cFos expression. J. Chem. Neuroanat. 21, 63-73. doi: 10.1016/s0891-0618(00)00092-2

Nicolle, M. M., Prescott, S., and Bizon, J. L. (2003). Emergence of a cue strategy preference on the water maze task in aged C57B6 x SJL F1 hybrid mice. Learn. Mem. 10, 520-524. doi: 10.1101/lm.64803

O'Keefe, J., and Nadel, L. (1978). The Hippocampus as a Cognitive Map. Oxford: Clarendon Press.

O'Leary, T. P., Savoie, V., and Brown, R. E. (2011). Learning, memory and search strategies of inbred mouse strains with different visual abilities in the Barnes maze. Behav. Brain Res. 216, 531-542. doi: 10.1016/j.bbr.2010. 08.030

Oliveira, A. M., Hawk, J. D., Abel, T., and Havekes, R. (2010). Post-training reversible inactivation of the hippocampus enhances novel object recognition memory. Learn. Mem. 17, 155-160. doi: 10.1101/lm.1625310

Packard, M. G. (1999). Glutamate infused posttraining into the hippocampus or caudate-putamen differentially strengthens place and response learning. Proc. Natl. Acad. Sci. U S A 96, 12881-12886. doi: 10.1073/pnas.96.22. 12881

Packard, M. G., and McGaugh, J. L. (1992). Double dissociation of fornix and caudate nucleus lesions on acquisition of two water maze tasks: further evidence for multiple memory systems. Behav. Neurosci. 106, 439-446. doi: 10.1037//07357044.106.3.439

Paul, C.-M., Magda, G., and Abel, S. (2009). Spatial memory: theoretical basis and comparative review on experimental methods in rodents. Behav. Brain Res. 203, 151-164. doi: 10.1016/j.bbr.2009.05.022

Pouliot, S., and Gagnon, S. (2005). Is egocentric space automatically encoded? Acta Psychol. (Amst) 118, 193-210. doi: 10.1016/j.actpsy.2004.10.016

Raz, N., Gunning, F. M., Head, D., Dupuis, J. H., McQuain, J., Briggs, S. D., et al. (1997). Selective aging of the human cerebral cortex observed in vivo: differential vulnerability of the prefrontal gray matter. Cereb. Cortex 7, 268-282. doi: 10.1093/cercor/7.3.268

Raz, N., Rodrigue, K. M., Kennedy, K. M., Head, D., Gunning-Dixon, F., and Acker, J. D. (2003). Differential aging of the human striatum: longitudinal evidence. AJNR Am. J. Neuroradiol. 24, 1849-1856.

Roberts, A. J., and Hedlund, P. B. (2012). The 5-HT(7) receptor in learning and memory. Hippocampus 22, 762-771. doi: 10.1002/hipo. 20938

Roberts, A. J., Krucker, T., Levy, C. L., Slanina, K. A., Sutcliffe, J. G., and Hedlund, P. B. (2004). Mice lacking 5-HT7 receptors show specific impairments in contextual learning. Eur. J. Neurosci. 19, 1913-1922. doi: 10.1111/j.1460-9568. 2004.03288.x

Rodgers, M. K., Sindone, J. A., and Moffat, S. D. (2012). Effects of age on navigation strategy. Neurobiol. Aging 33, 202.e15-202.e22. doi: 10.1016/j.neurobiolaging. 2010.07.021

Rubio, S., Begega, A., Mendez, M., Méndez-López, M., and Arias, J. L. (2012). Similarities and differences between the brain networks underlying allocentric and egocentric spatial learning in rat revealed by cytochrome oxidase histochemistry. Neuroscience 223, 174-182. doi: 10.1016/j.neuroscience.2012. 07.066

Sarkisyan, G., and Hedlund, P. B. (2009). The 5-HT7 receptor is involved in allocentric spatial memory information processing. Behav. Brain Res. 202, 2631. doi: 10.1016/j.bbr.2009.03.011

Shettleworth, S. J. (2009). Cognition, Evolution and Behavior. New York: Oxford University Press.

Small, S. A., Tsai, W. Y., DeLapaz, R., Mayeux, R., and Stern, Y. (2002). Imaging hippocampal function across the human life span: is memory decline normal or not? Ann. Neurol. 51, 290-295. doi: 10.1002/ana.10105

To, Z. P., Bonhaus, D. W., Eglen, R. M., and Jakeman, L. B. (1995). Characterization and distribution of putative 5-ht7 receptors in guinea-pig brain. Br. J. Pharmacol. 115, 107-116. doi: 10.1111/j.1476-5381.1995.tb16327.x 
Varnäs, K., Thomas, D. R., Tupala, E., Tiihonen, J., and Hall, H. (2004). Distribution of 5-HT7 receptors in the human brain: a preliminary autoradiographic study using [3H]SB-269970. Neurosci. Lett. 367, 313-316. doi: 10.1016/j.neulet.2004. 06.025

Waeber, C., and Moskowitz, M. A. (1995). Autoradiographic visualisation of $[3 \mathrm{H}] 5$-carboxamidotryptamine binding sites in the guinea pig and rat brain. Eur. J. Pharmacol. 283, 31-46. doi: 10.1016/0014-2999(95)00275-p

Walhovd, K. B., Westlye, L. T., Amlien, I., Espeseth, T., Reinvang, I., Raz, N., et al. (2011). Consistent neuroanatomical age-related volume differences across multiple samples. Neurobiol. Aging 32, 916-932. doi: 10.1016/j.neurobiolaging. 2009.05.013

Wiener, J. M., de Condappa, O., Harris, M. A., and Wolbers, T. (2013). Maladaptive bias for Extrahippocampal navigation strategies in aging humans. J. Neurosci. 33, 6012-6017. doi: 10.1523/JNEUROSCI.0717-12.2013

Yau, J. L., Noble, J., Widdowson, J., and Seckl, J. R. (1997). Impact of adrenalectomy on 5-HT6 and 5-HT7 receptor gene expression in the rat hippocampus. Brain Res. Mol. Brain Res. 45, 182-186. doi: 10.1016/s0169-328x(97) 00026-0

Yau, J. L., Olsson, T., Noble, J., and Seckl, J. R. (1999). Serotonin receptor subtype gene expression in the hippocampus of aged rats following chronic amitriptyline treatment. Brain Res. Mol. Brain Res. 70, 282-287. doi: 10. 1016/s0169-328x(99)00172-2
Zaehle, T., Jordan, K., Wüstenberg, T., Baudewig, J., Dechent, P., and Mast, F. W. (2007). The neural basis of the egocentric and allocentric spatial frame of reference. Brain Res. 1137, 92-103. doi: 10.1016/j.brainres.2006.12.044

Conflict of Interest Statement: The authors declare that the research was conducted in the absence of any commercial or financial relationships that could be construed as a potential conflict of interest.

Received: 22 September 2014; accepted: 15 December 2014; published online: 14 January 2015.

Citation: Beaudet G, Bouet V, Jozet-Alves C, Schumann-Bard P, Dauphin F, Paizanis E, Boulouard $M$ and Freret $T$ (2015) Spatial memory deficit across aging: current insights of the role of $5-\mathrm{HT}_{7}$ receptors. Front. Behav. Neurosci. 8:448. doi: 10.3389/fnbeh.2014.00448

This article was submitted to the journal Frontiers in Behavioral Neuroscience.

Copyright (C) 2015 Beaudet, Bouet, Jozet-Alves, Schumann-Bard, Dauphin, Paizanis, Boulouard and Freret. This is an open-access article distributed under the terms of the Creative Commons Attribution License (CC BY). The use, distribution and reproduction in other forums is permitted, provided the original author(s) or licensor are credited and that the original publication in this journal is cited, in accordance with accepted academic practice. No use, distribution or reproduction is permitted which does not comply with these terms. 